\title{
Geleitwort zur ersten Auflage
}

Die Kenntnis der in der Welt vorkommenden und heute angewandten Drogen bedingt ein umfangreiches Studium. Je mehr man lernt, um so mehr erkennt man die Größe und die erstaunliche Vielseitigkeit der Materie.

Der Wissenschaft verdanken wir bedeutende pharmakognostische Werke von hohem Wert und großer Gestaltungskraft.

Je mehr man sich jedoch in diese Werke vertieft und den Umfang des darin dargebotenen Stoffes erkennt, um so verständlicher wird der Wunsch vieler Kreise, eine tabellarisch gehaltene, bewußt eingeschränkte Darstellung über die heute bekanntesten Drogen zu besitzen, die in gedrängter Kürze und ohne wissenschaftliche Vertiefung Antwort auf die wesentlichen Fragen der täglichen Praxis erteilt.

Meine Tätigkeit als Obmann des Fachausschusses „Drogen“ der Wirtschaftsgruppe Groß-, Ein- und Ausfuhrhandel bringt mich mit allen Kreisen in Verbindung, die in irgendeiner Hinsicht auf dem Gebiet der Drogen tätig sind, und immer wieder verlautete der Wunsch nach einem Buch, das den geschilderten Anforderungen gerecht zu werden versucht.

Die Verwendung von Drogen bewegt sich in ansteigender Richtung, und in gleichem Maße wächst auch das Interesse, das diesem Arbeitsgebiet entgegengebracht wird.

Die Voraussetzung für ein eingehendes Studium unserer Drogen ist zunächst die Erkenntnis wesentlicher Fundamente, d. h. ein Wissen um Name und Art, Wirkstoff, allgemeinen Verwendungszweck und Herkunft der Stoffe.

Diesem Ziel dient das vorliegende Werk, und es ist damit klar, daß3 sich diese Arbeit nicht an die Wissenschaft wendet, deren Forschung sie ihr Entstehen verdankt, sondern vielmehr an die Praxis, die aus der hier gebotenen Darstellung die knappen Antworten erhält, die sie für ihre tägliche Arbeit nur zu oft benötigt. Der Verfasser sei bedankt dafür, daß er bei seinen Arbeiten diese Zielsetzung nicht verlor. Das Grundlegende, ohne eine Schilderung letzter Einzelheiten, macht den Wert seiner Arbeit aus.

Wer jemals damit begann, sich ernsthaft mit Drogen zu beschäftigen, wird dieses Buch gern zur Hand nehmen, um sein Wissen zu bereichern und aufzufrischen.

Vertieft man sich in die Materie, so wird man selten sagen können: ,ich weiß", um so häufiger aber: ,ich lerne“"!

Hamburg, im September I94I

lirich Blembel 
